\title{
Group Influences on Success Expectancies Regarding Social Influence Attempts ${ }^{1}$
}

\author{
Helmut Lamm ${ }^{2}$ \\ Universität Köln, West Germany
}

\begin{abstract}
Gisela Trommsdorf, Christine Burger, and Traudl Füchsle
Universität Mannheim, West Germany
\end{abstract}

This experiment concerned the generality of the discussion-induced shift toward pessimism found in some previous studies but not found in others. Male university students $(\mathrm{N}=95)$ were presented with one of two fictitious situations in which a protagonist wanted to gain compliance from another person (an employee wants a promotion; a parent wants his child to study more). For each of 16 compliance-gaining behaviors (e.g., promise, warning, invocation of need) the subjects had to indicate, on a 7-point scale, the likelihood that the protagonist would be successful ("objective response mode') or they had to indicate how well they personally could perform the respective influencing behavior ("subjective response mode'). All subjects first made a success-expectancy estimate. In the group condition (24 triads) participants discussed the judgmental issue and then again made a private estimate on each of the 16 items in turn. For the subjects in the control condition $(\mathrm{N}=23)$ group discussion was replaced by further individual thought and note-taking. Discussion-induced shifts toward pessimism were found in the group conditions $(\mathrm{p}<.01$ and .10 in the subjective and objective conditions). Since there was a (modest) overall initial tendency toward the pessimistic pole, this shift can in part be considered as group polarization, thus attesting to the generality of the group polarization phenomenon. (Secondary analyses bearing on the explanation of this

'This research was conducted at the Sonderforschungsbereich 24 (Sozial- und Wirtschaftspsychologische Entscheidungsforschung), Universität Mannheim, with financial support from the Deutsche Forschungsgemeinschaft and the Land Baden-Württemberg.

${ }^{2}$ Correspondence regarding this article and requests for reprints should be sent to Helmut Lamm, SFB 24, Universität, 68 Mannheim, West Germany. 
polarization are presented.) In addition, secondary analyses show that pessimistic shift also occurred in those discussion cases where there was no initial leaning toward pessimism. The theoretical explanation of these shifts is discussed.

\section{INTRODUCTION}

When considering how to attain a desired goal-in particular, how to influence another person so that he or she responds in the desired waypeople often estimate the likelihood of success. Also, quite often they discuss the chances of success with others (e.g., friends, family, associates). The present study was designed to investigate experimentally the effect of group discussion on likelihood estimates concerning the success of given social influence attempts.

\section{Existing Research Concerning Discussion \\ Effects on Expectancies}

The existing research concerning discussion effects on likelihood estimates presents an inconsistent picture.

The initial research in this area used the Choice Dilemmas questionnaire (Kogan \& Wallach, 1964), in which fictitious lifelike decision situations involving a risky course of action are presented (e.g., undergoing an operation, running for political office, buying stocks). Madaras and Bem (1968) and Lamm, Trommsdorff, and Kogan (1970) found that group discussion-to-consensus concerning the chances of success decreased the participants' probability estimates ("pessimistic shift"). In the lastmentioned study, whose results were by and large replicated by Schellenberg (1976), the effect is interpreted via the assumption that discussion centers on "'things that might go wrong,"' in other words, on conditions preventing the occurrence of the desired outcome. However, no relevant analyses of the discussion contents are presented.

The strong evidence on pessimistic shift with Choice-Dilemmas led us to consider its generality when real-life future events were involved. For this purpose we devised questionnaires listing a number of possible future attributes of one's own personal life or of one's society. In other words, several possible future conditions in various domains of life were enumerated, and subjects were asked to estimate the likelihood that the respective condition would exist by a certain time in the future. (For reasons 
of brevity we will use the term "future events" when referring to this research in the following.)

Lamm and Trommsdorff (1972) had groups discuss the likelihood that certain desirable social and political future events would have occurred by the year 2000 (e.g., 30-hour work week, peace in the Middle East). No directional shifts were found. Similarly, group discussion had no effect when undesirable social or political future events were involved (e.g. "Most city residents suffer from mental illness", "There is world-wide inflation") (Trommsdorff, 1978, experiment 2).

However, evidence of pessimistic shift was found in another experiment by Trommsdorff (1978, experiment 3 ). Women discussed the likelihood of occurrence of 12 events that might occur one or more times in their personal futures (e.g., "I have great self-confidence", "through several months I am very lonesome"). Discussion resulted in a shift toward pessimism (i.e., lower likelihood estimates) on the six desirable events, but not on the six undesirable events. She speculates that this shift is caused by self-presentation processes: subjects in the group context were reluctant to present too rosy a picture of themselves; they reduced their initial, more optimistic ("self-congratulatory") estimates in order to present a modestand, presumably, a more acceptable-picture of themselves.

Thus, there is evidence of pessimistic shift only in cases where desirable personal future events were involved (Madaras \& Bem, 1968; Lamm ci al., 1970; Trommsdorff, 1978, experiment 3). The interpretation of these pessimistic shifts favored by the respective investigators is largely speculative: prevalence of "obstacle" arguments and/or modest selfpresentation. It should be noted that these shifts were not instances of polarization since in all cases the average of the initial sample mean was almost exactly on, or even above, the midpoint of the 10-point probability scales [4.7 in the case of Lamm et al. (1970) and 6.2 in the case of Trommsdorff (1978)]. Group polarization refers to a discussion-induced enhancement of initial response tendencies (cf. Myers \& Lamm, 1976; Lamm \& Myers, 1978); there must be a distinct initial tendency toward one or the other pole for "group polarization" to apply. This means that the explanatory theories on group polarization-as they presuppose an initial response proclivity-do not apply in the above studies.

\section{Goals of the Present Study}

The present study was primarily intended as a further test of the generality of discussion-induced expectancy shifts. Would group discussion affect expectancies concerning social influence attempts? We again used 
(fictitious) situations of personal relevance. But this time the stimulus situations had a special structure: a goal (end-state) is given and along with it a number of possible ways to reach that goal. The goal is for person A (influence agent) to attain compliance from person B (target person). For example, a parent wants to get his/her child to do more school work. These response items describe ways to attain the goal.

Thus the response task - and the focus of group discussion-here is to judge the likelihood of success of certain social influence tactics in a given situation.

A second goal of the present study is to help settle the theoretical issue of explaining discussion-induced pessimistic shift. What are the social-psychological processes underlying the shift phenomenon?

As indicated above, two mechanisms have been suggested in the existing studies finding pessimistic shift: a preponderance of obstacle arguments and modest self-presentation. The former applies to both personal and nonpersonal future events. The latter applies only to personal future events, but not to nonpersonal events (an expectancy statement concerning the future of society does not reflect in any way on one's modest or immodest self-image). Since pessimistic shift was obtained only on personal future events, the modest self-presentation must be the preferable explanation at this point.

As yet there exists no empirical evidence relevant to the modest self-presentation thesis. In contrast, there is some evidence in support of the obstacle-arguments thesis. Trommsdorff (1978, experiment 3 ) analyzed the contents of the group discussions as well as of the notes ("internal dialogue") of the individuals in the control condition. She calculated the ratio of obstacle arguments (i.e., reasons given for the future occurrence of the events) to conductive arguments (reasons against the future occurrence). It was found that the relative level of obstacle arguments was greater in the group condition than in the control condition.

In order to enable an exploratory test of the two above explanatory theses-modest self-presentation and obstacle arguments-we will construct two kinds of situations (discussion groups): one in which the response task excludes self-presentation concerns and one in which such concerns are not excluded. The first will be called the objective condition (the subject is asked about the chances that "one" would be successful) and the other the subjective condition (the subject is asked about the chances that he personally would be successful). A significantly greater shift in the subjective condition would constitute evidence for the modest-selfpresentation thesis. 


\section{METHOD}

\section{Subjects}

Ninety-five male students at the Universität Mannheim participated as volunteers in this experiment, for which they were paid five Deutsche Mark per hour.

\section{Stimulus Materials}

Two of the four situations devised by Marwell and Schmitt (1966) were used as stimulus materials. Each of these situations describes a fictitious person (A) who wants to influence another person (B) toward a certain behavior. Sixteen behaviors for gaining person B's compliance are given. These behaviors had been devised by Marwell and Schmitt (1968) to exemplify the whole range of influence tactics suggested by French and Raven's (1959) theory of social power. A more detailed description of the instrument follows.

The sixteen types of compliance-gaining techniques are: promise, threat, mendation (predicting positive consequences), warning (predicting negative consequences), expression of liking, pregiving, aversive stimulation, invoking debt, moral appeal, predicting positive self-evaluation, predicting negative self-evaluation, altercasting (positive), altercasting (negative), appeal to altruism, predicting positive social evaluation, and predicting negative social evaluation.

The two situations chosen for this experiment were a "job situation" (trying to get a promotion from the boss) and a "family situation" (trying to get one's teenaged son to work harder in school). The job situation reads: "You have worked for a large exclusive clothing store for several years as a salesman. You have the best sales record in the store. You want Mr. Wilson, the owner of the store, to promote you to the position of sales manager which is now open." The family situation reads: "Your teenage son, Dick, who is a high-school student, has been getting poor grades. You want him to increase the amount of time he spends studying from 6 to 12 hours a week" (Marwell \& Schmitt, 1966, p. 356).

Two examples of sixteen compliance-gaining behaviors for the job situation are: "You offer to work 10 hours overtime per week until sales have risen by 20\%" (promise); "you tell B that other employees would not think highly of him if you do not get the salary raise" (predicting negative social 
evaluation). In the case of the family situation, examples of the same techniques are: "You of fer to increase Dick's allowance if he increases his studying" (promise); and "you tell Dick that the whole family will be very disappointed (in him) if he gets poor grades" (predicting negative social evaluation).

Depending on the response mode (one of our independent variables), the influence agent in the situation was presented either as "you" (as in the above examples) ("subjective response mode") or as "Mr. A" ("objective response mode").

Response Scale. In the subjective response mode condition, participants indicated, for each influence attempt, how well they personally could perform that behavior. A 7 point rating scale was provided, whose poles were labelled "extremely well" and "extremely badly". In the objective response mode condition, participants indicated, for each influence attempt, the likelihood that it would be successful if carried out in the given situaiton. Again a 7 point scale was given, whose poles were labelled "extremely likely" and "extremely unlikely".

\section{Design}

There were 24 triads participating in the group condition and 23 individuals participating in the control condition.

In the group condition participants responded to either the job situation or the family situation, either with the subjective or the objective response mode (see above). There were six groups in each of these four treatment combinations.

Similarly, in the control, participants responded either to the job situation or the family situation, either with the subjective or the objective mode.

\section{Procedure}

Group Condition. Upon arrival at the laboratory the three men were asked individually to respond to the given stimulus situation as described above. Thereupon they were placed around a table and were asked to discuss each of the 16 influencing behaviors for maximally 3 minutes, with regard to the given questions ("subjective response mode": competence of personal performance; "objective response mode": likelihood of success). After each discussion, participants were to indicate, individually, their positions on a new questionnaire sheet containing the same response scales. It was pointed out that this was not a memory test and that opinions might have changed as a result of new information. 
Control Condition. After having responded to the 16 compliancegaining behaviors, participants were asked to think about each of the 16 behaviors for maximally 3 minutes, with a view to the given question, and then indicate their position again in a new questionnaire sheet. They were given a 16-page booklet to note down their thoughts. It was noted that this was not a memory test and that opinions might have changed as a result of additional information.

\section{RESULTS}

\section{Shift}

For the group condition and for the control condition we conducted 2 $X 2$ analyses of variance (factor $\mathrm{A}$ : subjective vs. objective response mode; factor B: first vs. second measurement). Means and standard deviations are presented in Table $\mathrm{I}$.

For the group sample there was a significant main effect due to discussion $(F=9.28, d f=1 / 22, p<.006)$ : responses became more pessimistic through group discussion (lower estimates of competent performance in the subjective response mode condition, lower likelihood of success in the objective condition). No other significant or near-significant effects were obtained. $t$-tests showed that the discussion-induced shift was significant in the subjective condition $(t=2.87, d f=11, p<.01$, one-tailed) but only near-significant in the objective mode condition ( $t=$ 1.53, $d f=11, p<.10$, one-tailed) (see Table I).

For the control sample, the analysis of variance yielded only a main effect of response mode $(F=4.76, d f=1 / 22, p<.05)$ : responses were

Table I. Means and Standard Deviations for Success Expectancies ${ }^{a}$

\begin{tabular}{lllllll}
\hline & \multicolumn{2}{c}{$\begin{array}{c}\text { First } \\
\text { measurement }\end{array}$} & & \multicolumn{2}{c}{$\begin{array}{c}\text { Second } \\
\text { measurement }\end{array}$} \\
\cline { 2 - 3 } & $M$ & $S D$ & & $M$ & $S D$ & $t$ \\
\hline Group condition & & & & & \\
$\quad$ Subjective $(N=36)$ & 73.88 & 4.72 & & 79.17 & 5.21 & $2.87 c$ \\
$\quad$ Objective $(N=36)$ & 73.17 & 7.74 & & 76.42 & 7.25 & $1.53 b$ \\
Control condition & & & & & \\
$\quad$ Subjective $(N=11)$ & 77.91 & 16.67 & & 79.36 & 16.34 & \\
Objective $(N=12)$ & 67.75 & 5.50 & 69.00 & 10.45 & \\
\hline
\end{tabular}

${ }^{a}$ Higher values indicate greater pessimism. Values represent sums over the 16 items (compliance-gaining behaviors). In the group condition, $S D$ s are based on group scores.

$b_{p}<.10$ (one-tailed).

$c_{p}<.01$ (one-tailed) 
more pessimistic in the subjective than in the objective condition. This effect is of no theoretical interest here.

\section{Discussion Contents}

Tape recordings of the discussions of 20 of the 24 groups were obtained. The recordings for the four remaining groups could not be used, due to technical failure. (The shifts of these 4 discarded groups, over all 16 items, were $-20.33,-1.00,4.67$, and 5.67 , a negative sign indicating pessimistic shift.)

An independent judge, unaware of the hypotheses, categorized the discussion contents into arguments for or against pessimistic judgments (i.e., positions above or below the neutral point, or-verbally-no success or success). Only statements that contained genuine arguments-that is, reasons for favoring a given side of the judgmental issue-were included in the arguments category; mere statements of positions were not included. Nor were other kinds of statements included (e.g., opinions on the moral acceptability of a given compliance-gaining behavior). The judge indicated the direction of each argument, i.e., whether it was on the pessimistic or on the optimistic side.

To obtain a measure of the reliability of the directionality (optimistic vs. pessimistic) categorizations, a second independent judge, using the content units (arguments) established by the first, went over four protocols that had been randomly selected, one from each of the four objective/ subjective and job/family situation combinations. The agreement rate among the two judges regarding the directionality was extremely high: agreement existed on $90,54,52$, and 73 out of, respectively, 91, 55, 52, and 73 cases.

Thus we needed only one judge for this content analysis. For each group we computed the percentage of pessimistic arguments of the total number of arguments. The mean percentage was $63.5 \%$, which is significantly different from the $50 \%$ to be expected by a null hypothesis ( $t$ $=8.32, p<.002$, two-tailed).

For each of these 20 groups we computed correlations, across items $(d f=14)$, between percentage of pessimistic arguments and shift toward pessimism. The average size of these 20 correlations was $.42(p<.05$, onetailed). We also computed correlations, for each of the 16 items, across the 20 groups $(d f=18)$. The average size of these 16 correlations was $.54(p$ $<.01$, one-tailed). 


\section{DISCUSSION}

\section{Evidence for the Generality of Pessimistic Shift}

This experiment provided evidence of discussion-induced shift toward pessimistic judgments concerning events on the personal-as opposed to the societal-domain. The absence of shift in the control conditions permits the conclusion that the effect was not due to the repetition of measurements or to the effect of individual thought (cf. Tesser \& Conlee, 1975). Clearly this is a social effect, induced by group discussion.

\section{The Present Shift Is More than Group Polarization}

Evidence for Group Polarization. The shift toward pessimism found in the group condition may be - at least in part - a polarization effect since there is an initial response tendency: the average initial position is about 4.5 on the 7-point scale (remember that 7 is the pessimistic pole). The exact initial averages are 4.63 in the subjective condition and 4.51 in the objective condition. True, these values do not represent a very strong initial response tendency considering that Myers and Bishop (1971) use a criterion of one unit from the neutral point on a 7-point scale. Yet they indicate that-assuming an approximately normal distribution of initial responseson a sizable number of discussion cases there was a considerable intial tendency toward the pessimistic pole and there were very few cases where there was an initial tendency toward the optimistic pole. (By a "discussion case" we mean a discussion held by a group on a particular item. Thus, given 24 groups and 16 items, there are 384 discussion cases.)

The assumption of a polarization effect is supported by the significant across-item correlations between initial average and shift. [Indeed, Billig and Cochrane (1976) use such correlations as an index of group polarization.] Such correlation coefficients were calculated for each of the four combinations of stimulus situation (job, family) and response modes (subjective, objective) so that four correlation coefficients, each with fourteen degrees of freedom, were obtained. It should be noted that the signs of the shifts were reversed for those items on which the initial average was below the neutral midpoint, that is, below 4.00 , since we were interested in correlations between strength of initial response tendency and discussioninduced enhancement of that response tendency. The four correlation coefficients were -.17 (n.s.), $-.47(p<.05),-.55(p<.05)$, and .09 (n.s.) in 
the job/subjective, job/objective, family/subjective, and family/objective conditions. The respective average pessimistic shifts were $1.06,8.50,5.06$, and 2.17. Thus there were significant correlations in those treatment combinations where the pessimistic shift was significant.

In sum, this experiment provides evidence of group polarization using a judgmental response task that had not been considered in prior investigations (cf. Lamm \& Myers, 1978).

Directional Shift-beyond Group Polarization. However, there are indications that the discussion-induced pessimistic shift obtained in the present experiment cannot exhaustively be described as a group polarization effect.

If the present shift effects were entirely polarization effects, then there should be shifts toward optimism in those (few) discussion cases where there was a substantial initial leaning toward optimism. In order to empirically examine this possibility, we selected those cases on which the initial group average was below 3.00 , i.e., where there was an initial tendency toward the optimistic side, thus using the same criterion as Myers and Bishop (1971). There were 57 such cases out of a total of $384(=24 \times 16)$. The data analysis yielded no indication whatever of polarization (mean shift $-.04, t=.26$ ). This permits the conclusion that group discussion on the present stimulus task elicits a process operating toward pessimistic judgments, independently of polarization. This process acts as an inhibitor of the shift toward optimism that the "pure" group polarization concept would have led us to predict.

In an additional secondary analysis, we selected all discussion cases where there was no initial response tendency (i.e., where the initial group average was within one unit from the neutral point). There were 182 such cases $(M=4.19)$. A significant shift toward pessimism was found $(t=$ $2.30, d f=181, p<.05$, two-tailed).

Thus we have rather convincing evidence that the discussioninduced shift toward pessimism found in this experiment cannot exclusively be considered as group polarization.

\section{Theoretical Explanation}

As discussed above, our data provide evidence for group polarization as well as for a "pure" group-induced shift toward pessimism. This means that the overall shifts obtained here are caused by the processes generally underlying group polarization, as well as by additional, more specific processes applying only to pessimistic shift.

The theoretical explanations of group polarization have been reviewed by Lamm and Myers (1978). In the present case of group 
polarization the underlying process seems to be informational influence: due to the initial response tendency (i.e., a leaning toward pessimism), the production and exchange of arguments is biased toward the pessimistic side. Consistent with this assumption, we found a preponderance of discussion arguments for pessimistic judgments, as well as a correlation between pessimistic shift and preponderance of pessimistic arguments.

The "pure" pessimistic shift-that is, the shift that occurs in the absence of initial response tendencies toward pessimism-remains to be explained. As noted in the introduction, the pattern of existing findings (from other judgmental tasks) suggests that the most parsimonious explanation is that the group context motivates participants to present themselves as modest (i.e., not "showing off" with claims of high competence). In the present experiment we attempted to provide a (rather indirect) "test" of this explanation by comparing the effects in the subjective and objective response conditions. In the former an optimistic statement may be seen to imply that the speaker considers himself a competent performer, whereas in the latter it may imply only that anyone would be successful in carrying out the influence attempt. Our data do provide a bit of support for the modest-self-presentation thesis: only in the subjective condition was the pessimistic shift significant. However, there was no significant difference in amount of shift between the two conditions.

As a final note, it must be pointed out that self-presentation (or, more generally, social comparison) approaches to the explanation of choice shift (cf. Lamm \& Myers, 1978, sec. III D; Sanders \& Baron, 1977) contain an assumption that seems to be at odds with ours. As Jellison and Arkin (1977) suggest-and support by empirical evidence-group participants may be motivated to present themselves as competent and this causes a shift in the direction (e.g., more risk taking) thought to indicate greater competence. (Note that this assumption implies a prediction of shift toward optimism.) However, we submit that these two assumptions-modest self-presentation and competent self-presentation-do not contradict each other. Rather, in some situations and in some persons modesty may be the preferred image and in others competence may be the preferred image. Underlying both may be the desire to be attractive and acceptable to fellow group members (cf. Jones \& Wortman, 1973). Future research on these self-presentation dynamics in discussion groups may prove fruitful.

\section{REFERENCES}

BILLIG, M., \& COCHRANE, R. Judgements of values and group polarization: Tests of the value-for-risk hypothesis. European Journal of Social Psychology, 1976, 6, 495-501. 
BURNSTEIN, E., \& VINOKUR, A. Persuasive argumentation and social comparison as determinants of attitude polarization. Journal of Experimental Social Psychology, $1977,13,315-332$.

FRENCH, J. P. R., \& RAVEN, B. The bases of power. In D. Cartwright (Ed.), Studies in social power. Ann Arbor: University of Michigan Press, 1959.

JELLISON, J., \& ARKIN, R. Social comparison of abilities: A self-presentation approach to decision making in groups. In J. M. Suls \& R. L. Miller (Eds.), Social comparison processes. Washington, D.C.: Hemisphere, 1977.

JONES, E. E., \& WORTMAN, C. Ingratiation: An attributional approach. Morristown, N.J.: General Learning Press, 1973.

KOGAN, N., \& WALLACH, M. A. Risk taking: A study in cognition and personality. New York: Holt, Rinehart \& Winston, 1964.

LAMM, H., \& MYERS, D. G. Group-induced polarization of attitudes and behavior. In L. Berkowitz (Ed.), Advances in experimental social psychology (Vol. 11). New York: Academic Press, 1978.

LAMM, H., \& TROMMSDORFF, G. Group influences on probability judgments concerning social and political change. Psychological Reports, 1974, 35, 987-996.

LAMM, H., TROMMSDORFF, G., \& KOGAN, N. Pessimism-optimism and risk taking in individual and group contexts. Journal of Personality and Social Psychology, 1970, $15,366-374$.

MADARAS, G. R., \& BEM, D. J. Risk and conservatism in group decision-making. Journal of Experimental Social Psychology, 1968, 4, 350-365.

MARWELL, G., \& SCHMITT, D. R. Dimensions of compliance-gaining behavior: An empirical analysis. Sociometry, 1968, 31, 350-364.

MYERS, D. G., \& BISHOP, G. D. Enhancement of dominant attitudes in group discussion. Journal of Personality and Sociai Psychology, 1971, 20, 386-391.

MYERS, D. G., \& LAMM, H. The group polarization phenomenon. Psychological Bulletin, 1976, 83, 602-627.

SANDERS, G. S., \& BARON, R. S. Is social comparison irrelevant for producing choice shifts? Journal of Experimental Social Psychology, 1977, 13, 303-314.

SCHELlENBERG, J. A. Is there a pessimistic shift? Psychological Reports, 1976, 39, 359-362.

TESSER, A., \& CONLEE, M. C. Some effects of time and thought on attitude polarization. Journal of Personality and Social Psychology, 1975, 31, 262-270.

TROMMSDORFF, G. Gruppeneinflüsse auf Zukunftserwartungen. Meisenheim/Glan: Hain, 1978.

\section{BIOGRAPHICAL NOTES}

HELMUT LAMM received his PhD in Psychology from Princeton University after studies at various European universities and Dartmouth College. He is an author and coauthor of books on negotiation behavior and future orientation, and has published chapters and articles on small group processes, negotiation, justice, and future orientation. His current research concerns the social psychology of justice. He is a professor at the Universität Köln.

GISELA TROMMSDORFF received her PhD from Universität Mannheim after studies at German and U.S. universities. She is principal author (together with Burger, Füchsle, and Lamm) of Erziehung für die Zukunft (Education for the Future), published in 1978 by Schwann, Düsseldorf, and she authored a book on small-group influences on judgments concerning the future. She has published chapters and articles on small-group processes, negotiation, future orientation, and cross-cultural research. Her current research concerns future orientation and aggressiveness from a cross-cultural perspective. She is a professor at the Technische Hochschule Aachen. 
CHRISTINE BURGER received her Diploma in Psychology from the Universität Mannheim, where she is now a PHD Candidate. She is coauthor with Trommsdorff et al. of Erziehung für die Zukunft. Currently she is a scientific staff member at the Sonderforschungsbereich 24 (Sozialwissenschaftliche Entscheidungsforschung), Universität Mannheim, doing research on future orientation and delay of gratification.

TRAUDL FUCHSLE received her Diploma in Psychology from the Universität Mannheim, where she is now a PhD Candidate. She is coauthor with Trommsdorff et al. of Erziehung für die Zukunft. Currently she is a scientific staff member at the Sonderforschungsbereich 24 (Sozialwissenschaftliche Entscheidungsforschung), Universität Mannheim, doing research on future orientation and curiosity. 